\title{
Effect of Personal Innovativeness on Technology Adoption in Hospitality and Tourism: Meta-analysis
}

\author{
Olena Ciftci ${ }^{\left({ }^{凶}\right)}(\mathbb{D}$, Katerina Berezina $(\mathbb{D}$, and Minsoo Kang $(\mathbb{D}$ \\ University of Mississippi, University, MS 38677, USA \\ ociftci@go.olemiss.edu, \\ katerina@katerinaberezina.com, kang@olemiss.edu
}

\begin{abstract}
This study synthesizes existing empirical results about the effect of personal innovativeness on the intention to use technology in hospitality and tourism studies published from January 2010 to March 2020 via meta-analysis. The meta-analysis with a random effects model was conducted on 29 effect sizes of this relationship documented in 28 studies collected from over 7,000 search results on Google Scholar and Scopus. The results of the analysis suggest a significant positive medium effect of personal innovativeness on the intention to use technology in hospitality and tourism research with the overall effect size $(\mathrm{ESr})$ of $.38(95 \% \mathrm{CI}=.32, .44, \mathrm{z}=10.62, \mathrm{p}=.001)$. The study also found that the effect does not change significantly across industries (hotels, restaurants, and tourism and travel), types of technology by task (with transaction function and without transaction function), age groups (younger than 30 years old and 30 years old and older), and power distance cultural differences of the respondents (high-power distance and low-power distance cultures). Based on the results of this study, the authors suggest adding personal innovativeness as a construct in technology adoption models in future research in hospitality and tourism studies and continue investigating potential moderations that could explain variations in effect sizes of the impact of personal innovativeness on the technology adoption intention across different populations. From the industry perspective, hospitality and tourism organizations may rely on customers with high perceived innovativeness to serve as change agents and drive customer adoption of new technology.
\end{abstract}

Keywords: Personal innovativeness $\cdot$ Technology adoption $\cdot$ Meta-analysis

\section{Introduction}

Personal innovativeness is "the degree to which the individual is receptive to new ideas and makes innovation decisions independently of the communicated experience of others" ([17], p. 49 as cited in [18]). In the information technology context, customers with high personal innovativeness are more likely to have a positive perception of technological innovations $[1,25]$ and have the ability to overcome uncertainties related to using new technology [1]. Personal innovativeness is a personality trait that drives an individual's initial intention to try innovations, which precedes customer experience 
with any specific technology, therefore, making innovative customers an attractive group for businesses to initiate technology adoption and stimulate innovation.

According to the diffusion of innovation theory (DOI) by Rogers [24], early adopters and innovators (i.e., people with high personal innovativeness) may serve as technology advocates when a company is implementing new technologies. These two groups of people need little advertising and guidance, and, after trying a technology, they may turn into promoters and simply examples helping other customers embrace it. Therefore, companies that aim to implement technology may rely on innovators and early adopters as 'change agents' [1]. Additionally, these individuals may be recruited for early access to technology or purposefully targeted in a marketing campaign when the funds are limited. Thus, numerous previous studies on technology adoption included personal innovativeness as a factor influencing the willingness of an individual to use new technologies [e.g., 6, 22].

Research on technology adoption, including studies in hospitality and tourism, often relies on two theoretical frameworks to explain customer or employee adoption of technology. Those two models are the technology acceptance model (TAM) [7] and the unified theory of acceptance and use of technology (UTAUT) [27]. One of the two main outcomes of these models is the intention to use technology. In some studies, researchers use synonyms to this construct, including adoption intention, behavioral intention to use, willingness to use, or adopt.

Serving as a theoretical core, these two models have been modified by different researchers to increase the explanatory power of each model by introducing additional variables. Based on the DOI, personal innovativeness is often added as an antecedent of the intention to use technology. The studies in hospitality and tourism examine direct [e.g., 12, 20, 22] or indirect [e.g., 19, 26] effects of personal innovativeness on the intention to use technology. Or, in some studies, personal innovativeness is used as a moderator of the effect of other factors on the intention to use [e.g., 22]. Most of the studies hypothesize that personal innovativeness has a positive effect on the intention to use technology. But some studies found that there is no effect of personal innovativeness on the adoption intention of some types of technologies [4, 14, 15].

The conflicting results around the role of personal innovativeness in technology adoption may be explained by a variety of factors, such as the type of technology, industry segment that uses it, demographics, or cultural differences. From the type of technology perspective, research distinguishes between technology with the direct transaction function (e.g., mobile payments) and other self-service features (e.g., selfcheck-in) [2], and suggests that users perceive more severe potential negative consequences of technologies with transaction function in comparison with other technologies [16]. From the industry segment perspective, different segments of the hospitality industry, e.g., hotels, restaurants, tourism and travel, differ operationally and, therefore, may interact with the effect of personal innovativeness on the intention to use technology. At the user level, age was added as a moderator in the original UTAUT [27], and researchers in the field of technology adoption are still debating if adoption intentions can be different for younger and older users [13, 21]. And, from the perspective of cultural differences, power distance based on classification by Hofstede [11] may explain user reliance on technology adoption guidance provided by authorities and more powerful members of the society in high-power distance cultures [11], 
thus, leaving more room for the impacts of personal innovativeness on the intention to use technology in low-power distance cultures.

Given the results described above, the purpose of this study is to synthesize and clarify the effect and magnitude of the effect of personal innovativeness on technology adoption intention and factors that may change such effect. To the best of the authors' knowledge, there was no such study as of April 30, 2020. In order to achieve the purpose, the study sets the following objectives:

- To assess the overall size of the effect of personal innovativeness on the intention to use technology across different hospitality and tourism studies.

- To investigate the source and magnitude of moderator factors that may affect the overall effect size of the relation between personal innovativeness and the intention to use technology.

\section{Methods}

This study applies the meta-analysis method to achieve its objectives. Meta-analysis method allows to determine the magnitude of the studied effect by statistically synthesizing the results from independent studies [3]. The magnitude of an effect calculated via meta-analysis more precisely estimates the effect size across the population than any of the studies could do alone [3]. This method also allows to identify the range of effects and factors that change the magnitude of the effect size [3].

\subsection{Search Strategy and Selection Criteria}

The relevant studies for the meta-analysis were obtained from electronic databases Google Scholar and Scopus using the combinations of search words "personal innovativeness," "technology," and "adoption" with the following words: travel, tourism, hospitality, leisure, recreation, hotel, hostel, lodging, accommodation, restaurant, bar, travel agency, tour operator, travel agent, airport, airline, cruise, event, museum, casino, theme park, amusement park. The studies were collected for meta-analysis based on the following inclusion criteria:

1. The studies were published in peer-reviewed journals from January 2010 to March 2020. Information technology changes rapidly, so do the factors affecting technology adoption. This study focused on the last decade of research to capture the most current and relevant findings in this area.

2. The studies were written in the English language;

3. The studies were conducted in the hospitality and tourism context;

4. The studies included both personal innovativeness and intention to use technology, or either of the following constructs: adoption intention, willingness to use, behavioral intentions (if the items of the construct measure intention to use technology or social media) constructs; 
5. The studies used a quantitative methodology and reported correlation coefficients or regression coefficients of the relationship between the constructs of personal innovativeness and intention to use technology.

The search results lists were screened using a two-step approach to identify studies that meet inclusion criteria. First, the titles and sources of papers in each search list were manually screened for studies that meet criteria (1)-(3). After the duplicates were eliminated, the second screening of the articles' text was done to find articles that satisfy the criterion (4). The full text of the remaining articles was reviewed to identify whether or not the inclusion criterion (5) was met. Next, the reference lists of collected studies were manually reviewed for additional articles. However, no additional articles were found.

\subsection{Assessment of Methodological Quality of Individual Studies}

To assess the methodological quality of the studies included in the analysis, Downs and Black's Checklist [9] was modified to fit the specifics of methods used in social science studies. Questions with numbers 1, 2, 3, 4, 6, 10, 11, 12, 16, 18, 20, 22, 25, and 27 from original checklist remained in modified checklist. The studies were graded as zero (0) or one (1) point for each question on the checklist. The maximum total score of the modified Downs and Black's Checklist was 14 that represents the highest methodological quality of a paper.

\subsection{Data Extraction and Coding}

After the studies for meta-analysis were collected, the following categories of variables were extracted and coded from each of the studies included in the sample. ${ }^{1}$

1. Study characteristics: authors, study year, country where the research was conducted (they were coded into high-power distance and low-power distance cultures following classification by Hofstede [11]), industry (hotels, restaurants, tourism and travel);

2. Sample characteristics: sample size, population (customers, employees, or management),

3. Participants' age groups: only data from studies with age range cut-off at 30 years old were coded. While most of the studies reported age in different categories, a common cut-off of 30 years old was identified and used for the age group analysis. The studies were coded in two levels: studies with more than $60 \%$ of respondents younger than 30 years old and studies with more than $60 \%$ of respondents 30 years old and older;

4. Type of technology: technology type and task that was accomplished with technology were recorded but not coded for analysis (e.g., mobile applications for hotel check-in); technology type by task was coded in two levels, such as technology with transaction function (including, purchasing, booking, NFC, and financing) and

\footnotetext{
${ }^{1}$ The table with the individual studies' characteristics, topics, effect sizes and codes for the variables is available in the supplementary materials.
} 
without transaction function (e.g., social media, mobile apps for information search) as classified by Meuter et al. [16].

The effect size used in this meta-analysis is the Pearson correlation coefficient. The correlation coefficients were gathered from correlation or validity tables reported in the articles. If correlation coefficients were not available, standardized $\beta$ regression coefficients from the direct effect between personal innovativeness and intention were derived from articles. The standardized $\beta$ regression coefficients were transformed to correlation coefficients using Peterson and Brown's formula [23]:

$$
r=.98 \beta+.05 \lambda,
$$

where $\lambda=1$ when $\beta>=0$, and $\lambda=0$ when $\beta<0$.

\section{Analysis}

The study used a random effect model to calculate the mean effect size (ES) and 95\% confidence interval $(95 \% \mathrm{CI})$. ESs between .1 and .3 were interpreted as small, between .3 and .5 as medium, and greater than .5 as large according to Cohen's guidelines [5]. The present study used Cochran's $Q$ statistics to examine the heterogeneity of the mean ES [10]. The study also reports variance of true ES, $T^{2}$, with a standard deviation of true ES, $T ; I^{2}$ statistic that represents the percent of the variance in observed effects reflects variation in true effects, rather than sampling error; and a prediction interval. The moderator analyses via analog ANOVA were conducted to examine potential moderator variables' influence on the relationship between personal innovativeness and intention to use technology. The publication bias of the sample of studies was assessed based on the result of Egger's test of the regression intercept and by visually analyzing a funnel plot. All data analyses were conducted using JASP 0.11.1 software program.

Before meta-analysis, the correlation coefficients were converted into $\mathrm{z}$ scores using Fisher's r-to-z transformation [7]

$$
z_{r}=\frac{1}{2} \ln \left(\frac{1+r}{1-r}\right) .
$$

This transformation prevents sampling distribution error of correlation coefficients [8]. The Campbell Collaboration calculator [28] was used to transform correlation coefficients $r$ to Fisher's $z_{r}$ and compute $95 \%$ CI, and inverse variance weight for each study.

The data in Fisher's $z_{r}$ units were used as input for meta-analysis. To allow meaningful interpretation, results of the meta-analysis were transformed manually from the Fisher's z into correlation coefficients using Fisher's z-to-r transformation formula [8]

$$
r=\frac{e^{2 z_{r}}-1}{e^{2 z_{r}}+1}
$$


The results of the meta-analysis are reported in the form of both the Pearson correlation coefficient (ESr) and Fisher's z $\left(\mathrm{ESz}_{\mathrm{r}}\right)$ in the manuscript.

\section{Results}

\subsection{Study Characteristics}

The search on Google Scholar and Scopus resulted in 7,162 citations. After two screenings, duplicates elimination, and full-text review, 28 articles that met inclusion criteria remain for further analysis. ${ }^{2}$ The final sample for meta-analysis contained 29 effect sizes from 28 studies with a total of 10,106 participants. (see footnote 1)

\subsection{Methodological Quality of Individual Studies}

Based on the Downs and Black's checklist [9], the methodological quality of the included studies was robust [mean \pm standard deviation (SD) $11.39 \pm 1.95$ ] ranging from 7 to 14, considering the maximum score of 14 (see Table 1). No studies had quality scores outside three standard deviations of the mean; thus, data of all of the studies were used in the meta-analysis. Average scores for each measurement domain were: reporting (5 of 6), external validity (1.54 of 2), internal validity (4.68 of 5), and power $(.18$ of 1$)$.

Table 1. Modified Downs and Black's Checklist scores of the total sample

\begin{tabular}{l|l|l|l|l|l|l}
\hline & $\begin{array}{l}\text { Reporting } \\
\text { score (Out } \\
\text { of 6) }\end{array}$ & $\begin{array}{l}\text { External } \\
\text { validity score } \\
\text { (Out of 2) }\end{array}$ & $\begin{array}{l}\text { Internal validity - } \\
\text { bias score (Out of } \\
3)\end{array}$ & $\begin{array}{l}\text { Internal validity - } \\
\text { confounding score } \\
\text { (Out of 2) }\end{array}$ & $\begin{array}{l}\text { Power } \\
\text { (Out of } \\
\text { (O) }\end{array}$ & $\begin{array}{l}\text { Total } \\
\text { score (Out } \\
\text { of 14) }\end{array}$ \\
\hline Mean & 5.00 & 1.54 & 2.93 & 1.75 & .18 & 11.39 \\
\hline SD & .98 & .58 & .26 & .44 & .39 & 1.95 \\
\hline
\end{tabular}

\subsection{The Overall Strength of Effect Size}

The overall mean effect size of the Pearson correlation coefficient (ESr) is . 38 . The $95 \%$ $\mathrm{CI}$ is .32 to .44 , which tells us that the true mean ES in comparable studies could fall anywhere in this range (see Table 2 and Fig. 1). This range does not include zero, suggesting that the mean ES is different from zero. Similarly, the z-value for testing the null hypothesis (that mean ES is zero) is 10.62 with a p-value less than .001 . Thus, based on Cohen's guidelines, there is a significant positive, medium effect of personal innovativeness on the intention to use technology in hospitality and tourism research.

\footnotetext{
${ }^{2}$ PRISMA flow diagram that illustrates the number of papers that were accessed and removed from the sample on each stage of the data collection is available in the supplementary materials.
} 
Table 2. Results of meta-analysis

\begin{tabular}{|c|c|c|c|c|c|c|c|c|c|}
\hline \multirow[t]{2}{*}{$n$} & \multirow[t]{2}{*}{$N$} & \multirow[t]{2}{*}{$\mathrm{ES} z_{r}$} & \multirow[t]{2}{*}{$\mathrm{ES} r$} & \multirow[t]{2}{*}{$z$} & \multirow[t]{2}{*}{$p$} & \multicolumn{2}{|c|}{$95 \%$ CI $\left(z_{\mathrm{r}}\right)$} & \multicolumn{2}{|c|}{$95 \%$ CI $(r)$} \\
\hline & & & & & & $\begin{array}{l}\text { Lower } \\
\text { bound }\end{array}$ & $\begin{array}{l}\text { Upper } \\
\text { bound }\end{array}$ & $\begin{array}{l}\text { Lower } \\
\text { bound }\end{array}$ & $\begin{array}{l}\text { Upper } \\
\text { bound }\end{array}$ \\
\hline 29 & 10106 & .40 & .38 & 10.62 & $<.001$ & .33 & .48 & .32 & .44 \\
\hline
\end{tabular}

Note: $n=$ number of effect sizes; $N=$ total sample size; ES $z r=$ weighted mean ES in Fisher's z units; $\mathrm{ES} r=$ weighted mean ES in Pearson's $r$ units; 95\% CI $\left(\mathrm{z}_{\mathrm{r}}\right)=$ confidence interval in Fisher's $z$ units; 95\% CI $(r)=$ confidence interval in Pearson's $r$ units.

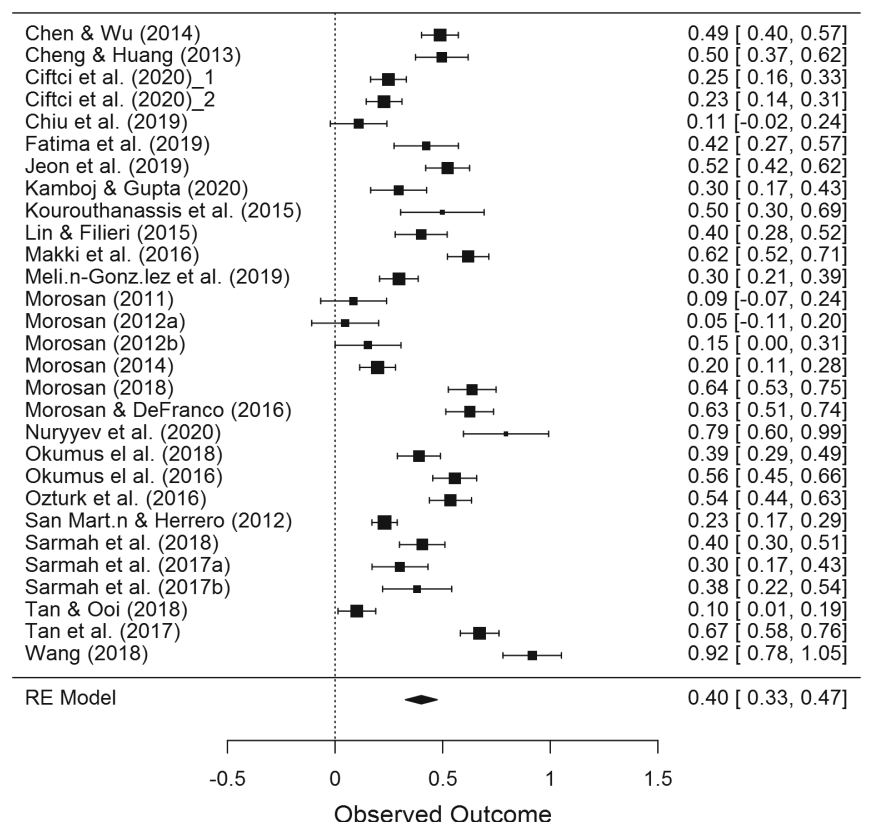

Fig. 1. Forest plot (presented in Fisher's $z_{\mathrm{r}}$ units).

\subsection{Variation in Effect Size}

The test of homogeneity of ES Q-statistic provides a test of the null hypothesis that all studies in the analysis share a common ES. The $Q$-statistic is 388.57 with $28 \mathrm{df}$ and a pvalue of less than .001 . Thus, the true ES is not identical in all the studies. The variance of true ES is $T^{2}=.04$, with a standard deviation of true ES is $T=.19$. The $I^{2}$ statistic is $92.79 \%$, which tells us that $92.79 \%$ of the variance in observed effects reflects variation in true effects, rather than sampling error.

The prediction interval is -.002 to .66 . Thus, the true ES can be as low as -.002 in some populations and as high as .66 on others. Based on the context outlined above, there will be some populations where the impact of the personal innovativeness on the intention to use technology is negative very close to zero and in some populations where the impact is positive large. 


\subsection{Moderator Analysis}

The moderator analysis via analog ANOVA revealed that the industry does not explain the variations of ESs. The Q statistics for model with industry was not statistically significant, $Q_{\text {between }}=.827, d f=2, p=.66$. Although there was no evidence of a moderator effect for industry, we found that the mean ESr for hotels and tourism and travel were not equal to zero (i.e., 95\% CI did not include zero) (see Table 3). Thus, there were significant positive, medium effects of personal innovativeness on the intention to use technology in studies about hotels $(\mathrm{ESr}=.43)$ and tourism and travel $(\mathrm{ESr}=.37)$ industries, respectively.

Table 3. Results of moderator analyses

\begin{tabular}{|c|c|c|c|c|c|c|c|c|}
\hline \multirow{2}{*}{$\begin{array}{l}\text { Moderator } \\
\text { variables }\end{array}$} & \multirow[t]{2}{*}{$\mathrm{n}$} & \multirow[t]{2}{*}{$\mathrm{ESz}_{\mathrm{r}}$} & \multirow[t]{2}{*}{$\mathrm{ESr}$} & \multicolumn{2}{|c|}{$95 \% \mathrm{CI}\left(\mathrm{z}_{\mathrm{r}}\right)$} & \multicolumn{2}{|c|}{$95 \% \mathrm{CI}(\mathrm{r})$} & \multirow[t]{2}{*}{$Q_{b}$} \\
\hline & & & & $\begin{array}{l}\text { Lower } \\
\text { bound }\end{array}$ & $\begin{array}{l}\text { Upper } \\
\text { bound }\end{array}$ & $\begin{array}{l}\text { Lower } \\
\text { bound }\end{array}$ & $\begin{array}{l}\text { Upper } \\
\text { bound }\end{array}$ & \\
\hline Industry & & & & & & & & .83 \\
\hline Hotels & 8 & .45 & .43 & .31 & .60 & .30 & .54 & \\
\hline Restaurants & 6 & .36 & .35 & -.01 & .72 & -.01 & .62 & \\
\hline $\begin{array}{l}\text { Tourism and } \\
\text { travel }\end{array}$ & 15 & .39 & .37 & .07 & .71 & .07 & .61 & \\
\hline \multicolumn{4}{|c|}{ Type of technology by tasks } & & & & & .004 \\
\hline Transaction & 14 & .41 & .39 & .30 & .52 & .29 & .47 & \\
\hline No transaction & 14 & .42 & .39 & .16 & .67 & .16 & .59 & \\
\hline Age & & & & & & & & .124 \\
\hline $\begin{array}{l}\text { At least } 60 \% \text { are } \\
\text { younger than } \\
30 \text { years old }\end{array}$ & 6 & .48 & .44 & .33 & .63 & .31 & .56 & \\
\hline $\begin{array}{l}\text { At least } 60 \% \text { are } \\
30 \text { years old and } \\
\text { older }\end{array}$ & 9 & .44 & .41 & .10 & .79 & .10 & .66 & \\
\hline \multicolumn{3}{|c|}{ Cultural power distance } & & & & & & 2.77 \\
\hline $\begin{array}{l}\text { High-power } \\
\text { distance }\end{array}$ & 14 & .45 & .42 & .34 & .55 & .33 & .50 & \\
\hline $\begin{array}{l}\text { Low-power } \\
\text { distance }\end{array}$ & 12 & .32 & .31 & .06 & .58 & .06 & .52 & \\
\hline
\end{tabular}

Note: All $\mathrm{p}>.05 ; \mathrm{n}=$ number of effect sizes; $\mathrm{ESz}_{\mathrm{r}}=$ weighted mean ES in Fisher's $\mathrm{z}$ units; $\mathrm{ESz}_{\mathrm{r}}=$ weighted mean ES in Pearson's $\mathrm{r}$ units; $Q b=$ Cochran's Q between statistics.

The type of technology by task does not explain the variations of ESs. The $Q$ statistics for the model with types of technology was not statistically significant, $Q_{\text {between }}=.004, d f=1, p=.949$. The mean ESr of both types of technology with and without transaction function are greater than zero (i.e., the $95 \% \mathrm{CI}$ (r) does not include zero) (see Table 3). Accordingly, personal innovativeness has a positive medium effect $(\mathrm{ESr}=.39)$ on the intention to use technology regardless of the type of technology. 
Age does not explain the variations of ESs either. The Q statistics for model with age was not statistically significant, $Q_{\text {between }}=.124, d f=1, p=.724$. Also, the $95 \% \mathrm{CI}$ (r) of both subgroups does not include zero (see Table 3 ). Thus, the personal innovativeness has a significant positive medium effect on the intention to use technology in the studies with more than $60 \%$ of respondents younger than 30 years old $(\mathrm{ESr}=.44)$ and the studies with more than $60 \%$ of 30 -year-old and older respondents in the samples $(\mathrm{ESr}=.41)$.

Cultural power distance does not explain the variations of ESs. The $Q$ statistics for model with cultural power distance was not statistically significant, $Q_{\text {between }}=2.77$, $d f=2, p=.10$. The mean ES of both high-power and low-power distance cultures subgroups are not equal to zero (i.e., 95\% CI (r) do not include zero) (see Table 3). Thus, the studies conducted in both high-power culture and lower-power countries will more likely find a significant positive medium effect of personal innovativeness on the intention to use technology $(\mathrm{ESr}=.42$ and $\mathrm{ESr}=.31$ accordingly).

\subsection{Publication Bias}

Egger's regression test was performed to examine the risk of bias across studies. Egger's test of regression intercept result shows no evidence of publication bias in this meta-analysis, $\mathrm{z}=.616$, two-tailed $\mathrm{p}$-value $=.538$. The funnel plot shows a symmetrical distribution ${ }^{3}$. Thus, there is no evidence of publication bias in the meta-analysis.

\section{Conclusions and Discussion}

This study is the first attempt to synthesize evidence of the effect of personal innovativeness on the intention to use technology across hospitality and tourism studies. The study results show that the overall ES of this effect is .38. Thus, the researchers have evidence of the medium, positive effect of personal innovativeness on the intention to use technology. However, according to the prediction interval, in some populations, the impact of the personal innovativeness on the intention to use technology may be null (true ES can be -.002) and, in other populations, the true ES of this effect can be as high as .66.

\subsection{Theoretical Contribution}

This study filled the void in the literature and reconciled the inconsistent findings regarding the effect of personal innovativeness on the technology adoption intention. Given the medium, positive effect of personal innovativeness on the intention to use technology, the authors of this study suggest including personal innovativeness in the technology adoption models. Interestingly, many of those articles that were excluded from the sample appeared in Google Scholar search results because they contained a recommendation to include personal innovativeness in future research. Thus, the

\footnotetext{
${ }^{3}$ The funnel plot is available in the supplementary materials.
} 
authors of those studies did not use the construct of personal innovativeness but acknowledged that it could be an influential factor for technology adoption. Therefore, the results of the current research substantiate the suggestion forwarded in prior studies.

Besides gaining the understanding of the overall effect of personal innovativeness on the intention to use technology, this study contributes to the scholarly debate about the moderation effect of age in technology adoption. This study found no moderation effect of age on the relationship between personal innovativeness and intention to use technology in hospitality and tourism settings. Also, the study results show a positive medium effect between the two constructs for the studies with more than $60 \%$ of people younger than 30 years old in the samples and the studies with more than $60 \%$ of people older than 30 years old. There were no moderating effects of industry, type of technology, or culture power distance characteristics found either.

\subsection{Practical Implications}

The results of this study indicate that personal innovativeness plays an important role in technology adoption in the hospitality and tourism setting despite the industry segment, type of technology, customer age, or power distance in the society. This means that people who perceive themselves innovative will use technology if they have access to it in all hospitality and tourism settings. Thus, hospitality businesses may benefit from building relationships with innovative consumers and rely on them to drive the technology adoption process. Hospitality businesses may want to identify customers with high perceived personal innovativeness and invite them to focus groups or think tank sessions for improving and developing technology-driven innovations within the organization. While opinions, wants, and needs of all customers should be heard, innovative customers may act as change agents to set examples for other less innovative customers. Also, some markets tend to have a higher density of innovative customers than others, and therefore, may be selected as technology testing grounds. And, finally, customers should be informed and educated about new technologies employed in the industry to encourage customers to use it with no regard to country, industry, or technology characteristics.

\subsection{Future Research Directions}

Overall, this study showed that personal innovativeness has a medium effect on the intention to use technology in the hospitality and tourism context. The findings also indicated heterogeneity of effect sizes of personal innovativeness on the technology adoption intention, however, failed to discover any moderators that would contribute to variations in effect sizes. The industry segment, technology type, user age, and social power distance did not reveal any statistically significant differences in effect sizes across the groups. Therefore, future research may continue to investigate the factors that may shed the light on the studied relationship. For example, this study was not able to make a comparison between customer and employee groups concerning personal innovativeness and technology adoption intentions due to the limitations of the sample size. The study population may be an interesting moderator to explore because employees may be more driven by an organizational mandate to adopt technology rather than by personal innovativeness. Also, moderator categories with wide 
confidence intervals around the identified effects may be explored further. For example, additional studies may be needed to flesh out the impact of personal innovativeness on technology adoption across restaurants of different service levels (e.g., quick service, fast-casual, casual, and fine dining). Finally, future research may conduct a metaanalysis of structural technology adoption models that include personal innovativeness with other antecedents of intention to use technology in hospitality and tourism.

\subsection{Limitations}

The study search was limited only to articles in English. Also, those articles that did not report correlation coefficients and regression coefficients were not included in the sample. The limitations of the study are also related to incomplete reporting of study data. Three studies included in the sample did not report sample characteristics at all or just stated that participants were students at a university, and three papers did not report a country of respondents' residency.

The study used data for analysis of the moderation effect of age only from 15 out of 28 studies that reported the age of the respondents in ranges with a cut-off at 30 years old. The other ten studies of the sample had a cut-off at 35 years old in the age ranges, and three studies did not report the age of the participants at all. Thus, only studies with the age range at 30 years old were suitable for moderating analysis and generalization. All the articles in the sample did not specify the mean and standard deviation (SD) of age respondents. So, the data did not allow us to use meta-regression with age as a moderator that could give more insights into the effect of age on the relationship between personal innovativeness and intention to use technology. If researchers have the opportunity to find the mean of age for each study, the results of moderating analysis of age on technology adoption could be a valuable addition to academic and practical knowledge. However, generally, reporting only age ranges is common practice in hospitality and tourism research.

The supplementary materials are available at https://drive.google.com/file/d/ 1YdVRr71GvKrvNQJ9-znPdt9jtIa17H2N/view?usp=sharing or upon request.

\section{References}

\section{References marked with an asterisk (*) indicate studies included in the meta-analysis. The full reference list of studies included in the meta-analysis sample available at https://drive.google.com/file/d/ 1YdVRr7lGvKrvNQJ9-znPdt9jtIa17H2N/view?usp=sharing or upon request.}

1. Agarwal R, Prasad J (1998) A conceptual and operational definition of personal innovativeness in the domain of information technology. Inf Syst Res 9(2):204-215

2. Blut M, Wang C, Schoefer K (2016) Factors influencing the acceptance of self-service technologies: a meta-analysis. J Serv Res 19(4):396-416 
3. Borenstein M, Hedges LV, Higgins JPT, Rothstein HR (2009) Introduction to meta-analysis. Wiley, Hoboken

4. *Ciftci O, Choi EK, Berezina K (2020) Customer intention to use facial recognition technology at quick-service restaurants. E-rev Tour Res 17(5):753-763

5. Cohen J (1988) Statistical power analysis for the behavioral sciences. L. Erlbaum Associates, London

6. Dabholkar PA, Bagozzi RP (2002) An attitudinal model of technology-based self-service: moderating effects of consumer traits and situational factors. J Acad Mark Sci 30(3):184-201

7. Davis FD, Bagozzi RP, Warshaw PR (1989) User acceptance of computer technology: a comparison of two theoretical models. Manage Sci 35(8):982-1003

8. DeCoster J (2009) Meta-analysis notes. https://www.stat-help.com/notes.html. Accessed 02 Mar 2020

9. Downs SH, Black N (1998) The feasibility of creating a checklist for the assessment of the methodological quality both of randomised and non-randomised studies of health care interventions. J Epidemiol Community Health 52(6):37-84

10. Higgins JP, Green S (eds) (2011) Cochrane handbook for systematic reviews of interventions 4. Wiley. https://training.cochrane.org/handbook

11. Hofstede G (2001) Culture's consequences: comparing values, behaviors, institutions and organizations across nations, 2nd edn. Sage, Thousand Oaks

12. *Kamboj S, Gupta S (2020) Use of smart phone apps in co-creative hotel service innovation: an evidence from India. Curr Issues Tour 23(3):323-344

13. Law M, Ng M (2016) Age and gender differences: understanding mature online users with the online purchase intention model. J Glob Sch Mark Sci 26(3):248-269

14. Liljander V, Gillberg F, Gummerus J, van Riel A (2006) Technology readiness and the evaluation and adoption of self-service technologies. J Retail Consum Serv 13:177-191

15. *Melián-González S, Gutiérrez-Taño D, Bulchand-Gidumal J (2019) Predicting the intentions to use chatbots for travel and tourism. Curr Issues Tour 1-19. https://doi.org/ 10.1080/13683500.2019.1706457

16. Meuter ML, Ostrom AL, Roundtree RI, Bitner MJ (2000) Self-service technologies: understanding customer satisfaction with technology-based service encounters. J Mark 64 (3):50-64

17. Midgley DF (1977) Innovation and new product marketing. Halsted Press, Wiley, New York

18. Midgley DF, Dowling GR (1978) Innovativeness: the concept and its measurement. J Consum Res 4(4):229-242

19. *Morosan C (2018) An empirical analysis of intentions to co-create value in hotels using mobile devices. J Hosp Tour Res 42(4):528-562

20. *Morosan C, DeFranco A (2016) Modeling guests' intentions to use mobile apps in hotels. Int J Contemp Hosp Manag 28(9):1968-1991

21. Natarajan T, Balasubramanian SA, Kasilingam DL (2018) The moderating role of device type and age of users on the intention to use mobile shopping applications. Technol Soc 53:79-90

22. *Okumus B, Ali F, Bilgihan A, Ozturk AB (2018) Psychological factors influencing customers' acceptance of smartphone diet apps when ordering food at restaurants. Int J Hosp Manag 72:67-77

23. Peterson RA, Brown SP (2005) On the use of beta coefficients in meta-analysis. J Appl Psychol 90(1):175-181. https://doi.org/10.1037/0021-9010.90.1.175

24. Rogers EM (2003) Diffusion of innovations, 5th edn. Free Press, New York

25. *San Martín H, Herrero Á (2012) Influence of the user's psychological factors on the online purchase intention in rural tourism: integrating innovativeness to the UTAUT framework. Tour Manag 33(2):341-350 
26. *Tan GWH, Ooi KB (2018) Gender and age: do they really moderate mobile tourism shopping behavior? Telematics Inform 35(6):1617-1642

27. Venkatesh V, Morris MG, Davis GB, Davis FD (2003) User acceptance of information technology: toward a unified view. MIS Q 27(3):425-478

28. Wilson DB (n.d.) Practical meta-analysis effect size calculator [Online calculator]. https:// campbellcollaboration.org/research-resources/effect-size-calculator.html. Accessed $01 \mathrm{Apr}$ 2020

Open Access This chapter is licensed under the terms of the Creative Commons Attribution 4.0 International License (http://creativecommons.org/licenses/by/4.0/), which permits use, sharing, adaptation, distribution and reproduction in any medium or format, as long as you give appropriate credit to the original author(s) and the source, provide a link to the Creative Commons license and indicate if changes were made.

The images or other third party material in this chapter are included in the chapter's Creative Commons license, unless indicated otherwise in a credit line to the material. If material is not included in the chapter's Creative Commons license and your intended use is not permitted by statutory regulation or exceeds the permitted use, you will need to obtain permission directly from the copyright holder. 